\title{
Colon perforation during percutaneous nephrolithotomy and fistula closure with Spongostan following conservative therapy
}

\author{
Sıtkı Ün, MD; Volkan Çakır, MD;† Osman Köse, MD;* Hakan Türk, MD; Y Yüksel Yılmaz, MD*
}

*Department of Urology, İzmir Katip Çelebi University, Atatürk Research and Training Hospital, Karabağlar/Izmir, Turkey; ${ }^{\dagger}$ Department of Radiology, İmir Katip Çelebi University, Atatürk Research and Training Hospital, Karabağlar/İzmir, Turkey; §Department of Urology, İzmir Tepecik Research and Training Hospital, Konak/Izmir, Turkey

Cite as: Can Urol Assoc J 2015;9(5-6):E313-5. http://dx.doi.org/10.5489/cuaj.2442 Published online May 13, 2015.

\section{Abstract}

Percutaneous nephrolithotomy (PCNL) is the first-line treatment for kidney stones. Colon perforation is a rare, but dangerous, complication. Colonic perforation might be very serious if it is not found early. After an unsuccessful extracorporeal shockwave lithotripsy, a 45-year-old female underwent a left-sided PCNL for two 1-cm kidney stones in the left kidney upper pole calyx. During dilatation, a colon perforation was suspected. The procedure was finished by inserting a 14Fr re-entry catheter into the colon. On postoperative day 5, a fluoroscopy was performed by injecting contrast dye through the re-entry catheter, which showed a fistula formation between skin and colon. The catheter was removed completely. A 16Fr external drainage catheter was inserted over the guidewire through the fistula tract. The fistula was closed by introducing prepared absorbable hemostatic gelatin powder (Spongostan) particles into the fistula tract through the catheter. Fistula tracks can be closed early by injecting absorbable Spongostan particles into the colonic fistula tract, thereby reducing inpatient time and increasing patient comfort.

\section{Introduction}

Percutaneous nephrolithotomy (PCNL) is a safe and reliable method in kidney stone surgery. ${ }^{1}$ However, even with more experience and technological advancements, complications are still frequent. Colon perforation is a rare, but dangerous, complication; its frequency occurs between $0.2 \%$ and $0.3 \%$ of the time. ${ }^{2,3}$ Colonic perforation might have serious consequences if it is not diagnosed early. ${ }^{4}$

\section{Case report}

A 45-year-old female underwent a left-sided PCNL for two 1 -cm kidney stones in the left kidney upper pole calyx after an unsuccessful extracorporeal shockwave lithotripsy. No anomalies (renal anomaly, retrorenal colon) were found in the preoperative computed tomography $(\mathrm{CT})$ review. The left ureter was catheterized and an 18-gauge access needle between the 11th and 12th rib was used to gain access into the upper pole. There was urine flow and the guidewire was inserted. Gradual dilation was performed using an Amplatz dilator up to $28 \mathrm{Fr}$. As the Amplatz renal sheath was introduced into the kidney, a change in the position of guidewire was marked. When the guidewire was followed using a nephroscope, a colon perforation was suspected. The area was confirmed as colon after contrast matter injection. After we injected a retrograde pelvicaliceal contrast through the ureter catheter, we did not find contrast extravasation in the colon or intra/extraperitoneal area.

The procedure was finished by inserting a $14 \mathrm{Fr}$ re-entry catheter into the colon. The ureter catheter was withdrawn and a double-J stent was placed into the ureter. The patient began dual antibiotic therapy (ceftriaxone-metronidazole) and oral feeding was stopped for 72 hours. Intravenous hydration was added. After 72 hours, oral feeding resumed since there were no complications. On postoperative day 5 , fluoroscopy was performed by injecting contrast dye through the re-entry catheter, which revealed a catheter in the colon (Fig. 1) and a fistula between the skin and colon (Fig. 2). A guidewire was inserted all the way to the colon through the catheter and then the catheter was removed completely. A 16Fr external drainage catheter was inserted over the guidewire through fistula tract. The fistula was closed by introducing prepared absorbable Spongostan particles into the fistula tract through the catheter. Using contrast dye, we closed the fistula (Fig. 3). The catheter was left proximal to the closed fistula track. After seeing no complications on postoperative day 7 , the catheter in the fistula track was removed. The patient was discharged without complications. Antibiotic treatment was prolonged to 14 days after discharge. A double-J stent was removed on postoperative day 30 at which time, no anomalies were detected on CT. 


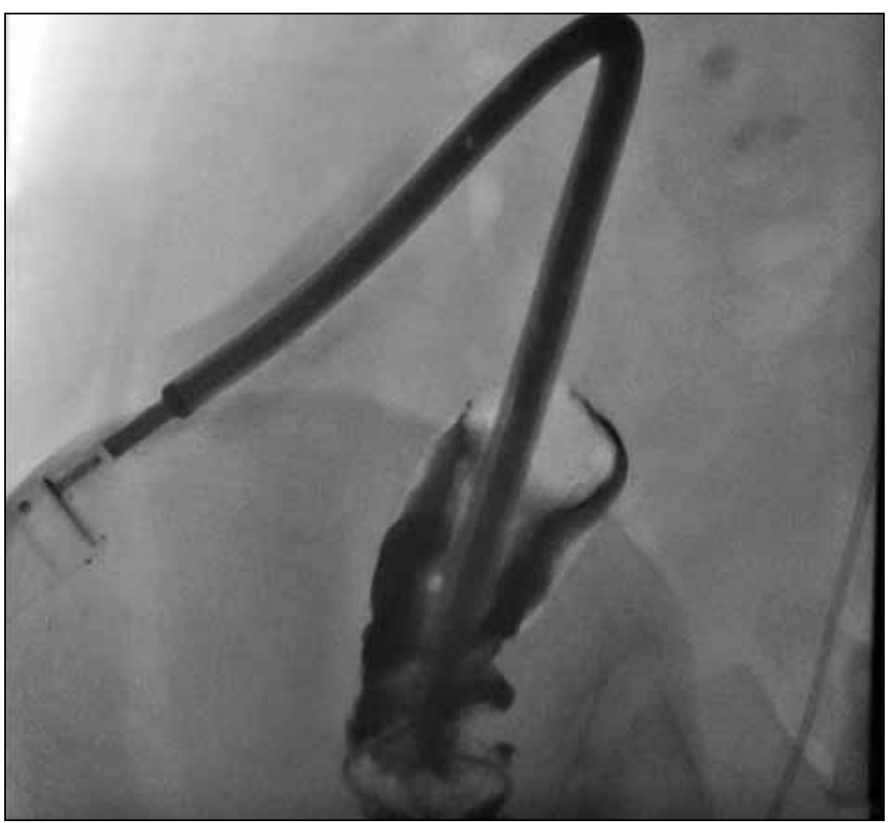

Fig. 1. Visualization of the colon with a re-entry catheter, which is placed into colon.

\section{Discussion}

Even though PCNL is a minimally invasive procedure, there are still complications. The most frequent complications are bleeding, pain, and fever which are relatively easy to manage. Pneumothorax and solid organ injuries are rare but serious complications. Colon injuries are also rare complications with a high morbidity and mortality risk. The frequency

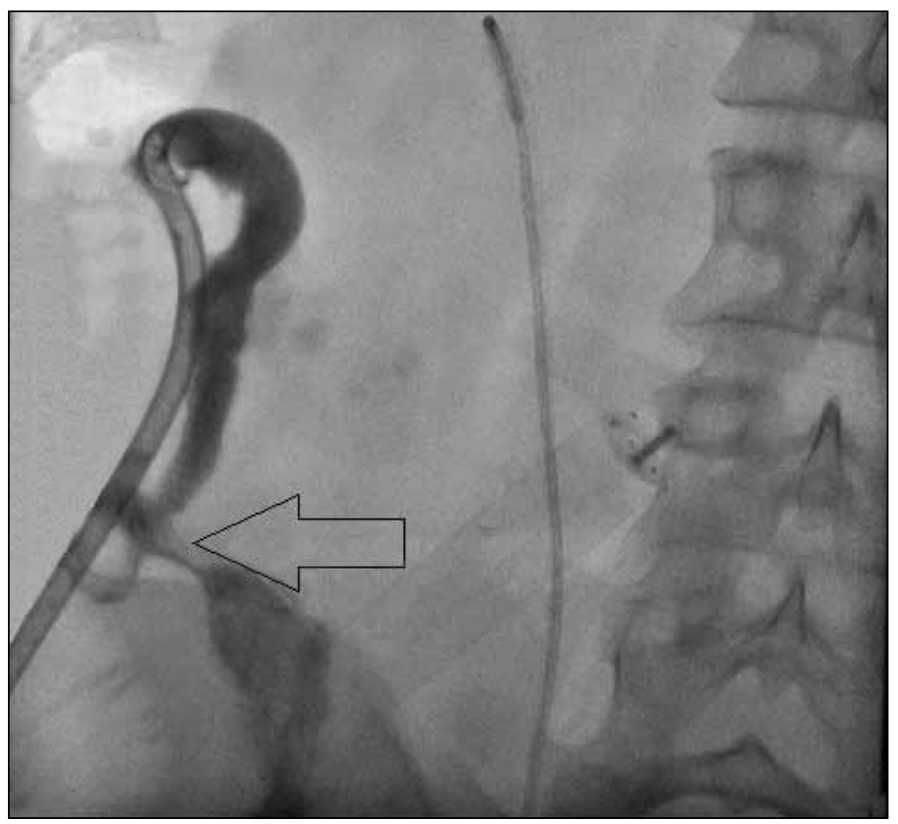

Fig. 3. Visualization of the fistula tract after closure by Spongostan.

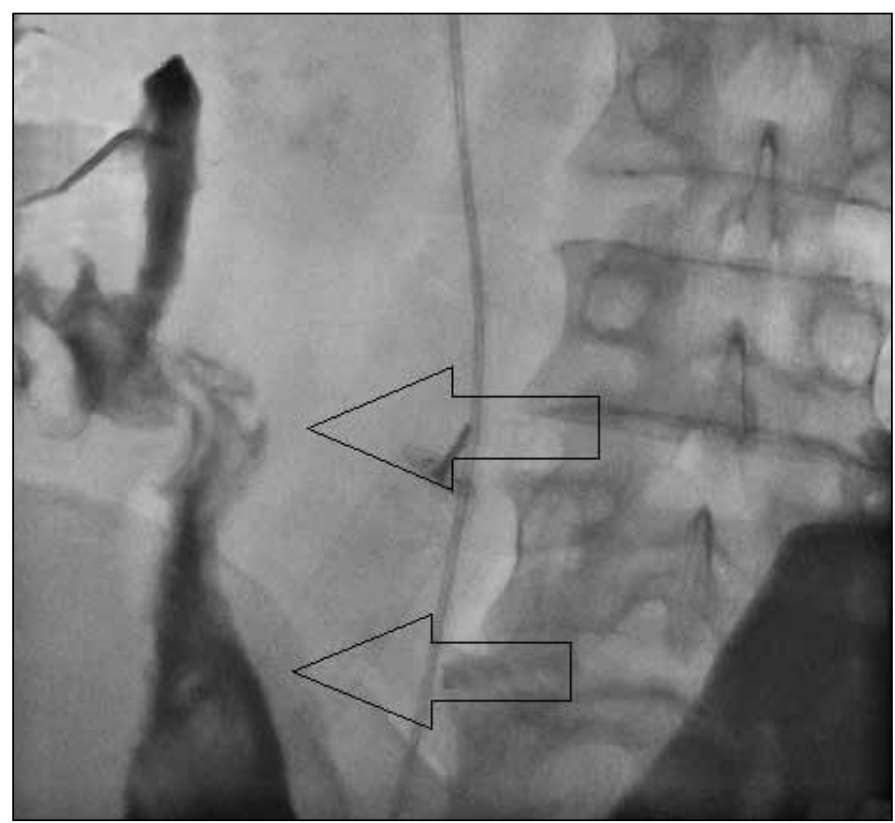

Fig. 2. Visualization of the fistula tract between the skin and colon.

is reported as $0.2 \%$ to $0.3 \% .^{3-5}$ Risk factors were age, dilated collecting tubules, horseshoe kidney, and retrorenal colon. ${ }^{6-9}$ In colon perforation cases, conservative management should be the first line of treatment. Colon and collecting tubules connection should be drained separately. Antibiotic therapy and ceasing oral feeding are recommended in these cases. ${ }^{7-10}$ Lately, fibrin sealants are recommended in persistent nephrocutaneous fistulas. ${ }^{10,11}$ Sposgostan has been used for fistulas in the gastrointestinal system. ${ }^{12,13}$ The mechanism of action of spongostan is supportive and mechanical. ${ }^{14}$ Fistula tracks can be closed early by injecting absorbable Spongostan particles into the colonic fistula tract, therefore reducing inpatient time and increasing patient comfort.

\section{Conclusion}

We think that closing the fistula tract by injecting Spongostan particles into the colonic fistula tract is effective and reliable.

Competing interests: The authors declare no competing financial or personal interests.

This paper has been peer-reviewed.

\section{References}

1. Ritter M, Krombach P, Michel M. Percutaneous stone removal. Eur Urol Suppl 201 1;10:433-9. http:// dx.doi.org/10.1016/i.eursup.2011.07.005

2. Skolarikos A, Alivizatos G, De La Rosette JJMCH. Percutaneous nephrolithotomy and its legacy. Eur Urol 2005;47:22-8. http://dx.doi.org/10.1016/i.eururo.2004.08.009 
3. AslZare M, Darabi MR, Shakiba B, et al. Colonic perforation during percutaneous nephrolithotomy: An 18-year experience. Can Urol Assoc J 2014;8:323-6. http://dx.doi.org/10.5489/cuaj.1646

4. El-Nahas AR, Shokeir AA, E-Assmy AM, et al. Colonic perforation during percutaneous nephrolithotomy: Study of risk factors. Urology 2006;67:937-41. http://dx.doi.org/10.1016/i.urology.2005.11.025

5. Mousavi-Bahar SH, Mehrabi S, Moslemi MK. Percutaneous nephrolithotomy complications in 671 consecutive patients: A single-center experience. Urol J 2011;8:271-6.

6. Kachrilas S, Papatsoris A, Bach C, et al. Colon perforation during percutaneous renal surgery: A 10-year experience in a single endourology centre. Urol Res 2012;40:263-8. http://dx.doi.org/10.1007/ s00240-012-0475-1

7. Vallancien $G$, Capdeville $R$, Veillon B, et al. Colonic perforation during percutaneous nephrolithotomy. J Urol 1985; 134:1185-7.

8. Noor Buchholz NP. Colon perforation after percutaneous nephrolithotomy revisited. Urol Int 2004;72:8890. http://dx.doi.org/10.1159/000075282

9. Rodrigues Netto N, Lemos GC, Fiuza JL. Colon perforation following percutaneous nephrolithotomy. Urology 1998;32:223-4. http://dx.doi.org/10.1016/0090-4295(88)90388-3
10. Miranda EP, Ribeiro GP, Almeida DC, et al. Percutaneous injection of fibrin glue resolves persistent nephrocutaneous fistula complicating colonic perforation after percutaneous nephrolithotripsy. Clinics 2009;64:711-3. http://dx.doi.org/10.1590/S1807-59322009000700017

11. Bradford TJ, Wolf JS. Percutaneous iniection of fibrin glue for persistent nephrocutaneous fistula after partial nephrectomy. Urology 2005;65:799. http://dx.doi.org/10.1016/i.urology.2004.10.079

12. Khairy GE, al-Saigh A, Trincano NS, et al. Percutaneous obliteration of duodenal fistula. J $R$ Coll Surg Edinb 2000;45:342-4.

13. Lisle DA, Hunter JC, Pollard CW, et al. Percutaneous gelfoam embolization of chronic enterocutaneous fistulas: Report of three cases. Dis Colon Rectum 2007;50:251-6. http://dx.doi.org/10.1007/s10350006-0772-2

14. Goodman LS, Gilman A. Surface-acting drugs. In: The Pharmacologic Basis of Therapeutics. 6th ed. New York: MacMillan Publishing Co.; 1980:955.

Correspondence: Dr. Sitki Ün, Department of Urology, İzmir Katip Çelebi University, Atatürk Research and Training Hospital, Çiğli Merkez/İzmir, Turkey; sitki@doctor.com 